\title{
Efficacy of mesalazine in IBS
}

Editor,

We read the papers by Barbara et $a l^{1}$ and Lam et $a l^{2}$ with interest. The authors reported the results of two randomised controlled trials (RCTs) of mesalazine in IBS. These are the largest studies examining the efficacy of this drug in IBS, to date, and the authors are to be applauded for conducting them.

The efficacy of mesalazine in UC is undisputed. $^{3-5}$ However, the observation that a subset of patients with IBS, particularly those with a post-infective aetiology, may demonstrate low-grade colonic mucosal inflammatory changes has led to a renewed interest in the use of the drug for this condition. ${ }^{6}$ Unfortunately, mesalazine was not superior to placebo in the authors' primary analysis in either of the trials, although there was a benefit in a posthoc analysis, when response to treatment was defined as satisfactory relief of overall IBS symptoms for a minimum of 10 weeks of the 12 -week treatment period in one trial ${ }^{1}$ and when mean daily stool frequency was assessed at study end in patients with the greatest daily stool frequency at baseline in the second trial. ${ }^{2}$

As the authors of one of the trials correctly point out, ${ }^{1}$ the landscape of trial design for RCTs in functional GI disorders has changed considerably since these two trials were conceived. This led to the use of endpoints for response that were probably too easily met by patients in the placebo arm, and which may partly explain the placebo response rates of almost 70\% for satisfactory relief of abdominal pain or discomfort, and $>60 \%$ for satisfactory relief of overall IBS symptoms in one trial ${ }^{1}$ and $>40 \%$ for satisfactory relief of IBS symptoms in the other. ${ }^{2}$

Increasing the stringency of the endpoint for response for satisfactory relief of IBS symptoms clearly led to an increase in the magnitude of the difference in response rates between mesalazine and placebo in 


\section{PostScript}

the trial by Barbara et al, from 4\% when response in 6 of 12 weeks was used to $11 \%$ when response in 9 of 12 weeks was used, through to $15 \%$ when response in 10 of 12 weeks was used (see figure $4 \mathrm{~B}$ of their article). However, there is another issue that may have led to an underestimation of the true treatment effect in both trials.

Efficacy of mesalazine in UC is equivalent whether given once daily or as divided doses. ${ }^{7}$ The literature on placebo response rates in IBS demonstrates that if a placebo is administered more than once daily, then placebo response rates rise. ${ }^{8}$ It may have therefore been preferable to use a once daily dosing schedule in both trials, in order to minimise placebo response rates, thereby increasing the likelihood of detecting a statistically significant difference between mesalazine and placebo.

This criticism aside, these are two excellent studies, which suggest that drugs that target mucosal inflammation may be beneficial in a subset of patients with IBS. Larger confirmatory RCTs conducted in these subgroups are anticipated eagerly.
Thazin Min, ${ }^{1}$ Alexander C Ford ${ }^{1,2}$

${ }^{1}$ Leeds Gastroenterology Institute, St. James's University Hospital, Leeds, UK

${ }^{2}$ Leeds Institute of Biomedical and Clinical Sciences, University of Leeds, Leeds, UK

Correspondence to Dr Alexander Ford, Leeds Gastroenterology Institute, Room 125, 4th Floor, Bexley Wing, St. James's University Hospital, Beckett Street, Leeds LS9 7TF, UK; alexf12399@yahoo.com

Contributors TM and ACF drafted the manuscript. Both authors have approved the final draft of the manuscript.

Competing interests None declared.

Provenance and peer review Not commissioned; internally peer reviewed.

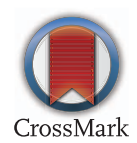

To cite Min T, Ford AC. Gut 2016;65:187-188.

Received 15 March 2015

Accepted 31 March 2015

Published Online First 14 April 2015

Gut 2016;65:187-188.

doi:10.1136/gutjnl-2015-309593

\section{REFERENCES}

1 Barbara G, Cremon C, Annese V, et al. Randomised controlled trial of mesalazine in IBS. Gut 2016;65: 82-90.

2 Lam C, Tan W, Leighton M, et al. A mechanistic multicentre, parallel group, randomised placebo-controlled trial of mesalazine for the treatment of IBS with diarrhoea (IBS-D). Gut 2016;65:91-9.

3 Ford AC, Achkar JP, Khan KJ, et al. Efficacy of 5-aminosalicylates in ulcerative colitis: systematic review and meta-analysis. Am J Gastroenterol 2011;106:601-16.

4 Feagan BG, MacDonald JK. Oral 5-aminosalicylic acid for induction of remission in ulcerative colitis. Cochrane Database Syst Rev 2012;10:CD000543.

5 Feagan BG, MacDonald JK. Oral 5-aminosalicylic acid for maintenance of remission in ulcerative colitis. Cochrane Database Syst Rev 2012;10:CD000544.

6 Barbara G, Stanghellini V, De Giorgio R, et al. Activated mast cells in proximity to colonic nerves correlate with abdominal pain in irritable bowel syndrome. Gastroenterology 2004;126:693-702.

7 Ford AC, Khan KJ, Sandborn WJ, et al. Once-daily dosing vs. conventional dosing schedule of mesalamine and relapse of quiescent ulcerative colitis: systematic review and meta-analysis. Am J Gastroenterol 2011;106:2070-7.

8 Ford AC, Moayyedi P. Meta-analysis: factors affecting placebo response rate in irritable bowel syndrome. Aliment Pharmacol Ther 2010;32:144-58. 